\title{
Patients' impressions of after-hours house-call services during the COVID-19 pandemic in Japan: a questionnaire-based observational study
}

Kojiro Morita* ${ }^{*}$, Ryota Inokuchi, Xueying Jin, Masatoshi Ishikawa and Nanako Tamiya

\begin{abstract}
Background: Access to healthcare has been strongly affected by the coronavirus disease 2019 (COVID-19) pandemic, which has raised concerns about the increased risk of delays in receiving medical care. This study aimed to assess the patients' impressions of after-hour house-call (AHHC) medical services during the COVID-19 pandemic using a patient questionnaire.
\end{abstract}

Methods: This was a cross-sectional observational study of anonymized medical record data and internet-based questionnaires from patients who used AHHC medical services from April 2020 to January 2021. We summarized the patients' impressions of AHHC medical services during the COVID-19 pandemic stratified by patient characteristics. The questions of the questionnaire were as follows: (i) Did you use the AHHC medical services because you suspected you had COVID-19 infection? (ii) Do you feel that the use of AHHC medical services has helped prevent transmission of COVID-19? (iii) What action would you have taken in the absence of AHHC medical services?

Results: A total of 1802 patients responded to the questionnaire (response rate: 11.3\%).

First, 700 (40.8\%) of the responders indicated that they had used AHHC medical services because of suspicion of COVID-19. Second, most responders (88.8\%) felt that AHHC medical services prevented transmission of COVID-19. Third, 774 (43.0\%) of the responders considered that they would have visited an emergency department or called an ambulance if AHHC medical services had not been used. Furthermore, 411 (22.8\%) of the responders indicated that they would remain at home or wait until working hours if AHHC medical services were not available despite having a condition that required emergency attention.

Conclusions: $\mathrm{AHHC}$ medical services may be one of the strategies for those who refrain from seeking healthcare services, thus reducing the risk of delayed hospital visits during emergencies. Furthermore, AHHC medical services may also contribute to preventing transmission of COVID-19 by avoiding contact with other patients in the hospital.

Keywords: After-hours house call, Emergency department, Out-of-hour service, Telephone triage

*Correspondence: kojirom@m.u-tokyo.ac.jp

Department of Health Services Research, University of Tsukuba, 1-1-1

Tenno-dai, Tsukuba, Ibaraki 305-8575, Japan

\section{Background}

Access to healthcare has been strongly affected by the coronavirus disease 2019 (COVID-19) pandemic. Several studies have revealed a significant reduction in emergency department (ED) visits and have raised concerns about the increased risk of delays in receiving 
hospital care for emergencies [1-5]. One of the reasons why patients have been refraining from visiting healthcare services has arisen from fear of COVID-19 infection while visiting hospitals or clinics $[1,6,7]$.

There are several models for out-of-hour care [8-11], and after-hour house-call (AHHC) medical services are services for semi-urgent cases or cases in which access to healthcare is difficult. In Tokyo, Japan, private AHHC medical services, which send doctors directly to patients' homes instead of an ambulance, have been available since 2016. This allows patients to receive medical services in their homes even if they do not have a family doctor. The AHHC service is not linked to any specific secondary care/Emergency Department (ED) services. The AHHC service will also directly request medical treatment from any hospital or call an ambulance if urgent treatment is needed. Before the establishment of the AHHC medical service, when a complaint occurs out-of-hours and patients were unable to arrange for a family doctor, patients are generally free to choose medical services as follows: (i) call an ambulance; (ii) visit to the ED by themselves; (iii) call a home clinic or hospital; (iv) call the telephone consultation service; or (v) wait until working hours.

Under the universal healthcare system, Japanese citizens have free access to public or even private medical facilities at any time, which allows people to visit any medical institution(s), such as hospitals or primary healthcare/family medicine facilities, regardless of their symptoms [12]. Furthermore, anyone can call an ambulance for free [13]. However, during out-of-hours periods (nights or holidays), most people cannot access their preferred medical facilities because these facilities do not always operate [14]. The emergency medical system is categorized into primary, secondary, and tertiary hospitals [15]. Generally, primary hospitals provide medical care for patients with mild symptoms who do not need hospital admission and can return home. Secondary hospitals provide emergency care for patients who potentially require hospital admission. Tertiary hospitals offer intensive care for critically ill patients who cannot be treated at primary or secondary emergency hospitals, such as acute myocardial infarction, stroke, or multiple injuries $[15,16]$. When patients use an ambulance, they are transported to secondary or tertiary hospitals depending on the severity of their condition. On the other hand, outpatients are also free to access primary, secondary, and even tertiary hospitals during out-ofhours periods.

It is important to understand the potential impact of effective AHHC medical services during the COVID-19 pandemic. AHHC medical services may also reduce the fear of acquiring COVID-19 infection in a hospital or clinic; however, there have been no questionnaire surveys to ask patients about their impressions of AHHC medical services during the COVID-19 pandemic. Therefore, we assessed the patients' impressions of AHHC medical services during the COVID-19 pandemic using questionnaires after AHHC medical services were used.

\section{Methods}

This was a cross-sectional observational study of anonymized medical record data and internet-based questionnaires from patients who used AHHC medical services from April 2020 to January 2021. The research ethics committee of the University of Tsukuba approved this study [approval number: 1527].

\section{Healthcare system in Japan AHHC medical services in Japan}

In Japan, public AHHC medical services are not available. Fast Doctor Ltd. (Shinjuku, Tokyo, Japan) has been operating as a private AHHC medical service in Tokyo since 2016, sending doctors to a patient's home during out-of-hours periods (18:00-6:00 on weekdays, 18:006:00 on Saturdays, and $24 \mathrm{~h}$ a day on Sundays and public holidays).

Patients can call AHHC medical services by phone. AHHC medical services have adopted the telephone triage system developed in the Tokyo Metropolitan Emergency Telephone Consultation Center of the Tokyo Fire Department [17]. Triage level is classified into five categories as follows: (i) red, a condition requiring transport to secondary or tertiary emergency hospitals with an ambulance; (ii) orange, a condition requiring immediate medical consultation at a secondary emergency hospital; (iii) yellow, a condition requiring medical consultation that might worsen; (iv) green, a non-urgent condition requiring primary care; and (v) white, a condition that can be observed at home [18]. AHHC medical services provide home-visit medical services only to patients classified as orange, yellow, and sometimes red based on the triage of the telephone consultation center.

Under the universal health insurance system in Japan, the health care/medical procedures are set in a national fee schedule, and patients pay the same price for the same medical care, regardless of which medical services they access. Patients who use AHHC medical services will be billed for transportation costs (up to about US\$9) in addition to their co-pay for the medical consultation.

\section{Data sources}

The study used anonymized medical record data and data of patient questionnaires conducted after patients had used AHHC medical services. 
The medical records included data on age, sex, telephone triage levels, primary diagnosis (using the International Classification of Diseases, Tenth Revision), disease severity, prescription of any drugs, time of medical examination, examination by health care personnel wearing personal protective equipment (PPE), screening with a diagnostic tool for COVID-19, and date of services. Reverse transcription-polymerase chain reaction [RT-PCR] for severe acute respiratory syndrome coronavirus 2 [SARS-CoV-2] or rapid antigen test for detection of SARS-CoV-2 had been used as a diagnostic tool for COVID-19 by doctors during medical examinations.

The disease severity was categorized into three levels based on the doctor's assessment after medical examinations as follows: (i) mild, a condition that could be treated with over-the-counter medications; (ii) moderate, a condition that required an ED visit if not using AHHC medical services; or (iii) severe, a condition that required an ambulance call if not using AHHC medical services.

AHHC medical service providers have been conducting an internet-based patient questionnaire survey about patients' impressions of AHHC medical services during the COVID-19 pandemic. The questionnaire consisted of three questions as follows: (i) Question on suspicion of COVID-19: "Did you use the AHHC medical services because you suspected you had COVID-19 infection? (Yes or No)"; (ii) Question on perception on prevention of transmission of COVID-19:" Do you feel that the use of AHHC medical services has helped prevent transmission of COVID-19? (Yes or No)"; and (iii) Question on possible actions if AHHC medical services were not available:" What action would you have taken in the absence of AHHC medical services (stay home, wait for consultation until a hospital opens, visit the ED, or call an ambulance)?".

The patients themselves or their caregivers responded to the questionnaire.

\section{Study population}

We selected AHHC medical service users whose medical record data and data of patient questionnaires existed from April 11, 2020, to January 31, 2021. In Japan, to combat the COVID-19 outbreak, the Japanese government proclaimed an emergency declaration from April 8, 2020, for Tokyo and six other prefectures. The state of the emergency declaration was expanded to the entire country on April 16, 2020. Under Japanese law, the government does not have the authority to implement a lockdown. However, based on this declaration, the government requested to refrain from going out of the house unnecessarily, closed various offices, businesses or schools, and encouraged home working [19].

\section{Statistical analysis}

First, we compared the patient characteristics (age, sex, first triage color, diagnosis, disease severity, prescription of any drugs, examination by health care personnel wearing PPE, diagnostic tools for COVID-19, and time of medical examination) between questionnaire responders and non-responders. Pearson's chi-square test was used to compare the proportions of categorical variables between the groups. The t-test was used to compare the time of medical examination, a continuous variable.

Second, we summarized patients' impressions of AHHC medical services during the COVID-19 pandemic stratified by patient characteristics.

All statistical analyses were conducted using Stata/MP version 14 (Stata Corp., College Station, TX, USA), and the level of significance was set at $\mathrm{p}<0.05$.

\section{Results}

A total of 15,998 patients used AHHC medical services during the study period. A total of 1802 patients responded to the patient questionnaire (response rate: $11.3 \%)$.

\section{Comparison of patient characteristics between questionnaire responders and non-responders}

A total of 10,595 patients $(66.2 \%)$ were aged $\geq 16$ years, and the triage color of 8548 patients' was orange (53.4\%). The top three primary diagnostic categories were respiratory, infectious, and digestive diseases. A total of 8775 patients who used AHHC medical services (54.9\%) had a condition that could be treated with over-the-counter drugs, and 310 patients (1.9\%) would have required an ambulance had AHHC medical services not been used. Drug prescriptions from AHHC medical services were provided to $81.6 \%$ of the patients, and the average medical examination time was $29.4 \mathrm{~min}$. A total of $50.3 \%$ of patients were examined by health care personnel wearing PPE, and $21.9 \%$ of patients were screened using diagnostic tools for COVID-19 (Table 1). Overall, 759 (4.7\%) patients were diagnosed with COVID-19 (data not shown).

Responders to the questionnaire were more likely to be older (mean age (years [ \pm standard deviation]): 31.3 [ \pm 24.9$]$ vs. 27.4 $[ \pm 22.6] ; \mathrm{p}<0.001)$, less likely to receive any drug prescription $(79.9 \%$ vs. $81.8 \% ; \mathrm{p}=0.049)$, more likely to be examined by health care personnel wearing PPE (53.6\% vs. $49.9 \% ; \mathrm{p}=0.003)$, and more likely to be screened with diagnostic tools for COVID-19 (25.0\% vs. 21.5\%; $\mathrm{p}<0.001)$ than non-responders. However, there were no clinically significant differences between the two groups (Table 1). 
Table 1 Patient characteristics in responders and non-responders

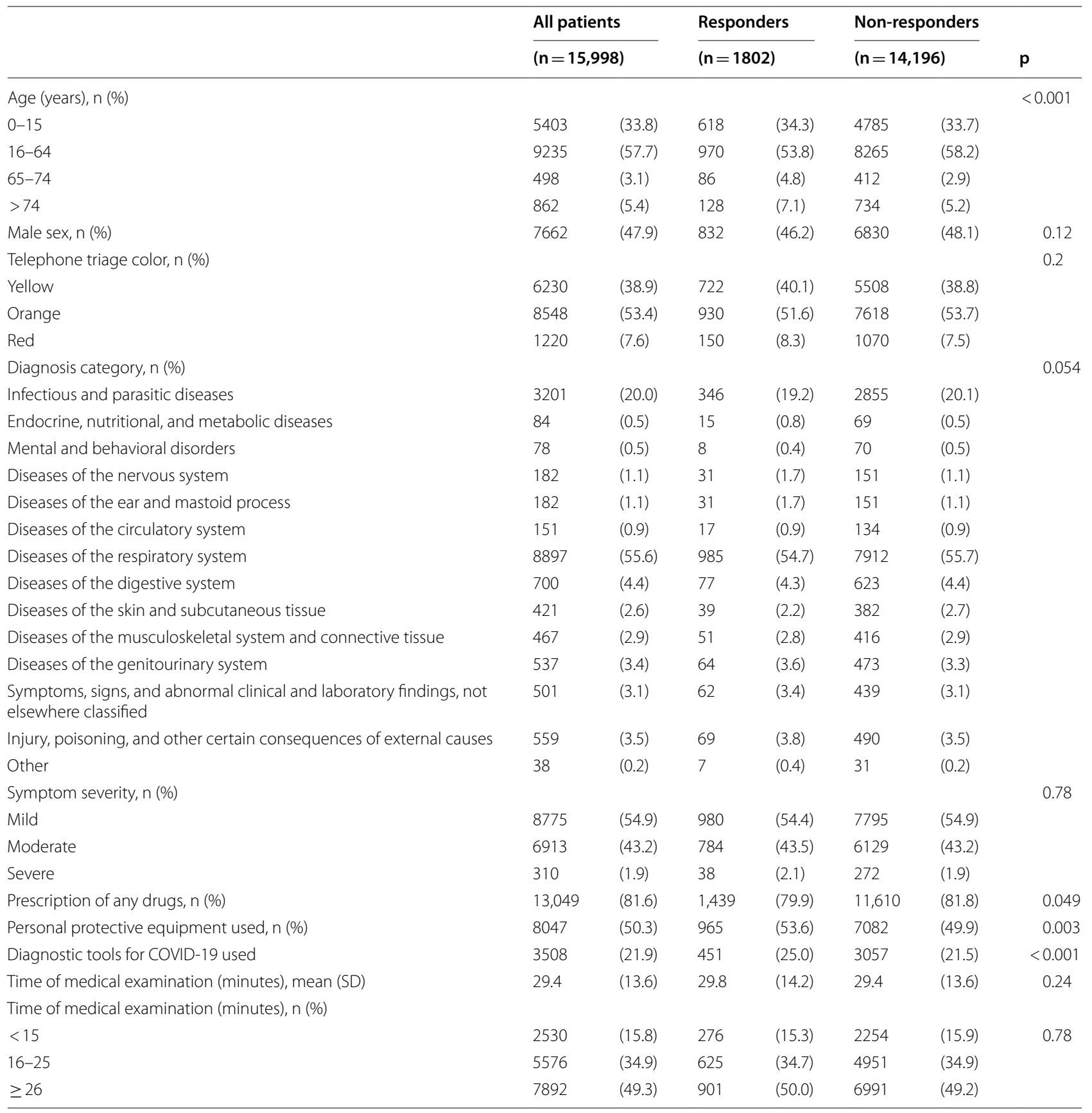

Abbreviations: $A H H C$ after hour house call, COVID-19 coronavirus disease 2019, ED emergency department, SD standard deviation

\section{Patients' impressions of AHHC medical services} during the COVID-19 pandemic

Figure 1 displays the results of patient questionnaires after AHHC medical services. Of the responders, 40.8\% used AHHC medical services because of suspected COVID-19. Furthermore, regardless of suspicion of COVID-19, the majority (89.0\%) of responders who received $\mathrm{AHHC}$ medical services felt that $\mathrm{AHHC}$ medical services helped prevent transmission of COVID-19. A total of 774 out of 1802 (43.0\%) considered that they would have visited an ED (634 patients, 35.2\%) or called an ambulance (140 patients, 7.8\%) if AHHC services were not used. On the other hand, $55.4 \%$ of responders answered that they would "remain at home" or "wait until working hour" if AHHC medical services were not available. 
(i) Did you use the AHHC medical services because you suspected you had COVID-19 infection?
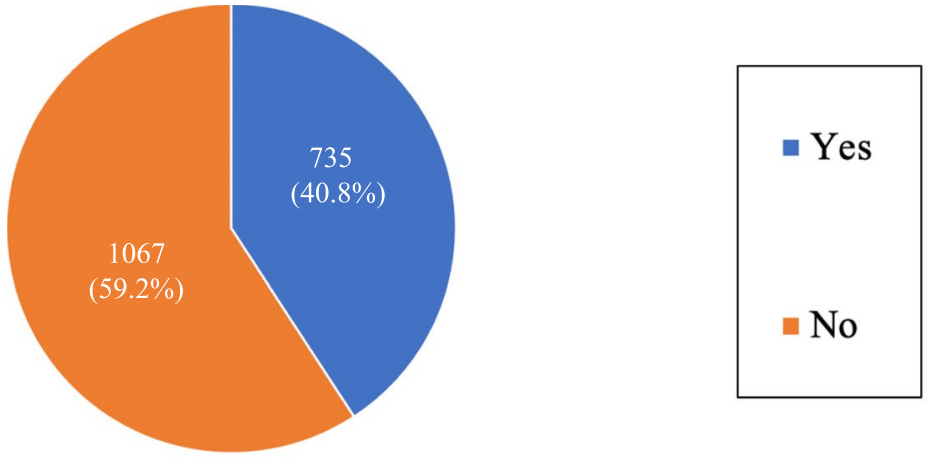

(ii) Do you feel that the use of AHHC medical services has helped prevent transmission of COVID-19?
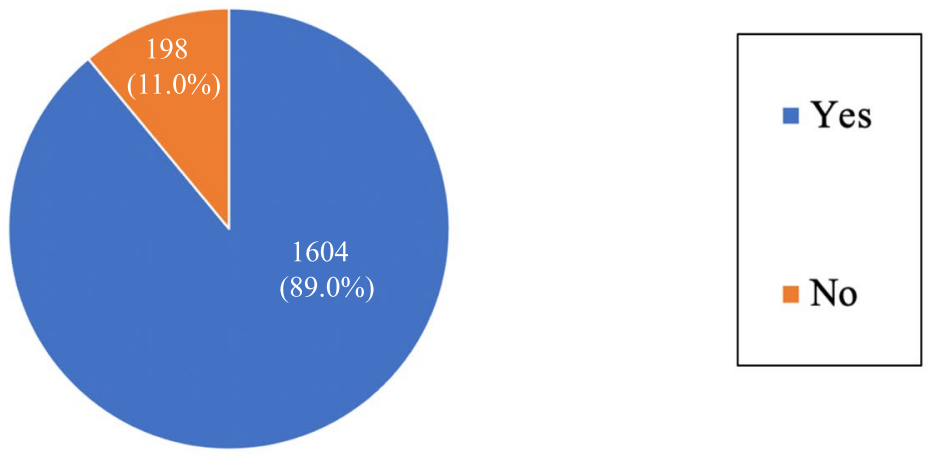

(iii) What action would you have taken in the absence of AHHC medical services?

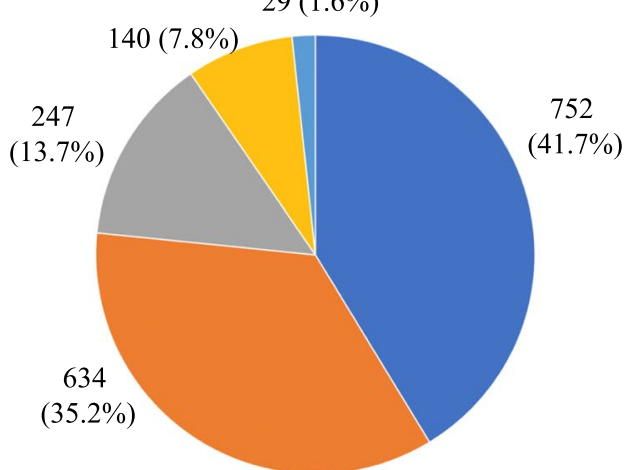

$$
\begin{aligned}
& \text { - Wait until working hours } \\
& \text { - Visit emergency department } \\
& =\text { Remain at home } \\
& =\text { Call ambulance } \\
& =\text { Other }
\end{aligned}
$$

Fig. 1 The results of the patient questionnaires after AHHC medical service use

Patient characteristics according to suspicion of COVID-19 Table 2 shows the patient characteristics based on whether the patients suspected themselves of having COVID-19 infection or not (based on the question "Did you use the AHHC medical services because you suspected you had COVID-19 infection?"). The patients with the following characteristics and the medical services to patients presenting symptoms were more likely to feel that their symptoms may be related to COVID-19: (i) age 16-74 years; (ii) orange triage color; (iii) mental/behavioral disorder or respiratory illness; (iv) mild symptom severity (a condition that could be treated with over-thecounter medications); (v) examination by health care personnel wearing PPE or screening with a diagnostic tool 
Table 2 Patient characteristics based on whether the patients suspected themselves of having COVID-19 infection or not ${ }^{\mathrm{a}}$

\begin{tabular}{|c|c|c|c|c|c|}
\hline & $\begin{array}{l}\text { Whether } \\
\text { COVID-19 }\end{array}$ & $\begin{array}{l}\text { patient } \\
\text { ection } 0\end{array}$ & ted themsel & s of having & \\
\hline & Yes & & No & & $p$ \\
\hline & $\begin{array}{l}(n=735) \\
(40.8 \%)\end{array}$ & & $\begin{array}{l}(n=1067) \\
(59.2 \%)\end{array}$ & & \\
\hline Age (years), n (\%) & & & & & $<0.001$ \\
\hline $0-15$ & 165 & $(26.7)$ & 453 & $(73.3)$ & \\
\hline $16-64$ & 495 & $(51.0)$ & 475 & $(49.0)$ & \\
\hline $65-74$ & 35 & $(40.7)$ & 51 & $(59.3)$ & \\
\hline$>74$ & 40 & (31.3) & 88 & $(68.8)$ & \\
\hline Telephone triage color, n (\%) & & & & & $<0.001$ \\
\hline Yellow & 254 & $(35.2)$ & 468 & $(64.8)$ & \\
\hline Orange & 425 & $(45.7)$ & 505 & $(54.3)$ & \\
\hline Red & 56 & $(37.3)$ & 94 & $(62.7)$ & \\
\hline Diagnosis category, n (\%) & & & & & $<0.001$ \\
\hline Infectious and parasitic diseases & 100 & $(28.9)$ & 246 & $(71.1)$ & \\
\hline Endocrine, nutritional, and metabolic diseases & 4 & $(26.7)$ & 11 & (73.3) & \\
\hline Mental and behavioral disorders & 4 & $(50.0)$ & 4 & $(50.0)$ & \\
\hline Diseases of the nervous system & 4 & $(12.9)$ & 27 & $(87.1)$ & \\
\hline Diseases of the ear and mastoid process & 4 & $(12.9)$ & 27 & $(87.1)$ & \\
\hline Diseases of the circulatory system & 1 & (5.9) & 16 & $(94.1)$ & \\
\hline Diseases of the respiratory system & 565 & $(57.4)$ & 420 & $(42.6)$ & \\
\hline Diseases of the digestive system & 11 & $(14.3)$ & 66 & $(85.7)$ & \\
\hline Diseases of the skin and subcutaneous tissue & 4 & $(10.3)$ & 35 & $(89.7)$ & \\
\hline Diseases of the musculoskeletal system and connective tissue & 4 & $(7.8)$ & 47 & $(92.2)$ & \\
\hline Diseases of the genitourinary system & 13 & $(20.3)$ & 51 & $(79.7)$ & \\
\hline $\begin{array}{l}\text { Symptoms, signs, and abnormal clinical and laboratory findings, not else- } \\
\text { where classified }\end{array}$ & 8 & $(12.9)$ & 54 & $(87.1)$ & \\
\hline Injury, poisoning, and other certain consequences of external causes & 10 & $(14.5)$ & 59 & $(85.5)$ & \\
\hline Other & 3 & $(42.9)$ & 4 & $(57.1)$ & \\
\hline Symptom severity, n (\%) & & & & & $<0.001$ \\
\hline Mild & 443 & $(45.2)$ & 537 & $(54.8)$ & \\
\hline Moderate & 285 & $(36.4)$ & 499 & $(63.6)$ & \\
\hline Severe & 7 & $(18.4)$ & 31 & $(81.6)$ & \\
\hline Personal protective equipment used, $n$ (\%) & 557 & $(57.7)$ & 408 & $(42.3)$ & $<0.001$ \\
\hline Diagnostic tools for COVID-19 used, n (\%) & 377 & $(83.6)$ & 74 & $(16.4)$ & $<0.001$ \\
\hline Time of medical examination (minutes), mean (SD) & 31.8 & $(14.7)$ & 28.5 & (13.6) & $<0.001$ \\
\hline Time of medical examination (minutes), n (\%) & & & & & $<0.001$ \\
\hline$<15$ & 83 & $(30.1)$ & 193 & $(69.9)$ & \\
\hline $16-25$ & 233 & $(37.3)$ & 392 & $(62.7)$ & \\
\hline$\geq 26$ & 419 & $(46.5)$ & 482 & $(53.5)$ & \\
\hline
\end{tabular}

a Statistically significant variables are shown

Abbreviations: AHHC after hour house call, ED emergency department, SD standard deviation, COVID-19 coronavirus disease 2019

for COVID-19; and (vi) medical examination time of more than $26 \mathrm{~min}$.
Patient characteristics according to patients' perception on prevention of transmission of COVID-19

Table 3 shows the patients' perception on the role of AHHC medical services in helping prevent the transmission of COVID-19 (based on the question "Do you feel that the use of AHHC medical services has helped 
Table 3 Patients' perception of prevention of transmission of COVID-19 stratified by patient characteristics ${ }^{\mathrm{a}}$

\begin{tabular}{|c|c|c|c|c|c|}
\hline & \multicolumn{4}{|c|}{$\begin{array}{l}\text { Do you feel that the use of AHHC medical services has } \\
\text { helped prevent transmission of COVID-19? }\end{array}$} & \multirow{3}{*}{$p$} \\
\hline & \multirow{2}{*}{$\begin{array}{l}\text { Yes } \\
(n=1604) \\
(89.0 \%)\end{array}$} & & \multicolumn{2}{|l|}{ No } & \\
\hline & & & $\begin{array}{l}(n=198) \\
(11.0 \%)\end{array}$ & & \\
\hline Age (years), n (\%) & & & & & $<0.001$ \\
\hline $0-15$ & 577 & $(93.4)$ & 41 & (6.6) & \\
\hline $16-64$ & 839 & $(86.5)$ & 131 & $(13.5)$ & \\
\hline $65-74$ & 71 & $(82.6)$ & 15 & $(17.4)$ & \\
\hline$>74$ & 117 & $(91.4)$ & 11 & $(8.6)$ & \\
\hline Diagnosis category, n (\%) & & & & & $<0.001$ \\
\hline Infectious and parasitic diseases & 304 & $(87.9)$ & 42 & $(12.1)$ & \\
\hline Endocrine, nutritional, and metabolic diseases & 15 & $(100.0)$ & 0 & $(0.0)$ & \\
\hline Mental and behavioral disorders & 6 & $(75.0)$ & 2 & $(25.0)$ & \\
\hline Diseases of the nervous system & 25 & $(80.6)$ & 6 & $(19.4)$ & \\
\hline Diseases of the ear and mastoid process & 28 & $(90.3)$ & 3 & $(9.7)$ & \\
\hline Diseases of the circulatory system & 15 & $(88.2)$ & 2 & $(11.8)$ & \\
\hline Diseases of the respiratory system & 912 & (92.6) & 73 & $(7.4)$ & \\
\hline Diseases of the digestive system & 63 & $(81.8)$ & 14 & $(18.2)$ & \\
\hline Diseases of the skin and subcutaneous tissue & 31 & $(79.5)$ & 8 & $(20.5)$ & \\
\hline Diseases of the musculoskeletal system and connective tissue & 35 & (68.6) & 16 & $(31.4)$ & \\
\hline Diseases of the genitourinary system & 56 & $(87.5)$ & 8 & $(12.5)$ & \\
\hline $\begin{array}{l}\text { Symptoms, signs and abnormal clinical and laboratory findings, not else- } \\
\text { where classified }\end{array}$ & 49 & $(79.0)$ & 13 & $(21.0)$ & \\
\hline Injury, poisoning, and other certain consequences of external causes & 59 & $(85.5)$ & 10 & $(14.5)$ & \\
\hline Other & 6 & $(85.7)$ & 1 & $(14.3)$ & \\
\hline Symptom severity, n (\%) & & & & & $<0.001$ \\
\hline Mild & 898 & $(91.6)$ & 82 & (8.4) & \\
\hline Moderate & 680 & $(86.7)$ & 104 & $(13.3)$ & \\
\hline Severe & 26 & $(68.4)$ & 12 & $(31.6)$ & \\
\hline Personal protective equipment used & 895 & $(92.7)$ & 70 & $(7.3)$ & $<0.001$ \\
\hline Diagnostic tools for COVID-19 used & 439 & $(97.3)$ & 12 & (2.7) & $<0.001$ \\
\hline Time of medical examination (minutes), mean (SD) & 30.1 & $(14.3)$ & 27.2 & $(12.3)$ & 0.007 \\
\hline Time of medical examination (minutes), n (\%) & & & & & 0.028 \\
\hline$<15$ & 234 & $(84.8)$ & 42 & $(15.2)$ & \\
\hline $16-25$ & 554 & $(88.6)$ & 71 & $(11.4)$ & \\
\hline$\geq 26$ & 816 & $(90.6)$ & 85 & $(9.4)$ & \\
\hline
\end{tabular}

${ }^{a}$ Statistically significant variables are shown

Abbreviations: AHHC after hour house call; COVID-19 coronavirus disease 2019, ED emergency department, SD standard deviation

prevent transmission of COVID-19?"), stratified by patient characteristics.

Patients under 15 years or over 75 years of age; with endocrine, nutritional, and metabolic diseases; with respiratory diseases; with diseases of the ear and mastoid process; examined by health care personnel wearing PPE; screened with diagnostic tools for COVID-19; and with a medical examination time of $26 \mathrm{~min}$ or more were more likely to feel that AHHC medical services prevented transmission of COVID-19. On the other hand, the group with severe symptoms (a condition that requires ambulance if not using an AHHC) had a higher proportion of "No" on whether AHHC medical services helped prevent transmission of COVID-19. 


\section{Possible actions if AHHC medical services were not available}

Based on the question "What action would you have taken in the absence of AHHC medical services", patients aged 16-64 and 65-74 years were more likely to report that they would wait until working hours if AHHC medical services were not available than the overall proportion.

When patients suspected themselves of having COVID-19 infection, these patients were more likely to report that they would visit the ED or call an ambulance if AHHC medical services were unavailable. Conversely, these patients were less likely to report waiting until working hours if AHHC medical services were unavailable.

Even among the responders who indicated that they would remain at home or wait until working hours if AHHC medical services were not available, some patients had moderate $(398 / 1802)$ or severe $(13 / 1802)$ symptoms based on the physician's assessment (Table 4).

\section{Discussion}

The present study found that (i) about $40 \%$ of the questionnaire responders used AHHC medical services because they suspected themselves of having COVID19 infection; (ii) the majority of questionnaire responders who received $\mathrm{AHHC}$ medical services felt that these services can prevent transmission of COVID-19; (iii) and $43.0 \%$ of questionnaire responders considered that they would have visited an ED or called an ambulance if AHHC services were not available. This situation was more apparent if they suspected themselves of having COVID-19 infection. Furthermore, among those who used AHHC services between April 2020 and January 2021, half of the patients were examined by health care personnel wearing PPE, and about $20 \%$ of the patients were screened using diagnostic tools for COVID-19.

First, to the best of our knowledge, this is the first study to describe the characteristics of AHHC medical service users during the COVID-19 pandemic. Several patient characteristics and the medical services to patients presenting symptoms were associated with the patients' perception of suspicion of COVID-19 infection, such as diagnosis of respiratory diseases, examination by health care personnel wearing PPE, and screening with a diagnostic tool for COVID-19. The AHHC medical services used PPE in patients with fever, and the presence of fever or respiratory symptoms may have been a factor in patients' perception of suspicion of COVID-19. Previous studies have shown that the number of ED visits was reduced during the COVID-19 pandemic, even in cases of respiratory diseases and infections [20-22]. Therefore, patients with COVID-19 may use AHHC medical services. Indeed, $4.7 \%$ of patients were diagnosed with COVID-19.

Second, this survey revealed that most patients who were considered to require medical consultation by telephone triage felt that AHHC medical services were useful for preventing transmission of COVID-19. This

Table 4 Possible actions if AHHC medical services were not available stratified by patient characteristics

\begin{tabular}{|c|c|c|c|c|c|c|c|c|c|c|c|}
\hline \multirow{4}{*}{$\begin{array}{l}\text { Characteristic } \\
\text { Age (years), n (\%) }\end{array}$} & \multicolumn{10}{|c|}{ Expected actions if no use of $\mathrm{AHHC}$ medical services } & \multirow{4}{*}{$\begin{array}{l}\mathbf{p} \\
<0.001\end{array}$} \\
\hline & \multicolumn{2}{|c|}{ Remain at home } & \multicolumn{2}{|c|}{$\begin{array}{l}\text { Wait until } \\
\text { working hours }\end{array}$} & \multicolumn{2}{|c|}{ Visit the ED } & \multicolumn{2}{|c|}{$\begin{array}{l}\text { Call an } \\
\text { ambulance }\end{array}$} & \multicolumn{2}{|c|}{ Other } & \\
\hline & \multicolumn{2}{|c|}{$\begin{array}{l}(n=247) \\
(13.7 \%)\end{array}$} & \multicolumn{2}{|c|}{$\begin{array}{l}(n=752) \\
(41.7 \%)\end{array}$} & \multicolumn{2}{|c|}{$\begin{array}{l}(n=634) \\
(35.2 \%)\end{array}$} & \multicolumn{2}{|c|}{$\begin{array}{l}(n=140) \\
(7.8 \%)\end{array}$} & \multicolumn{2}{|c|}{$\begin{array}{l}(n=29) \\
(1.6 \%)\end{array}$} & \\
\hline & & & & & & & & & & & \\
\hline $0-15$ & 70 & $(11.3)$ & 250 & $(40.5)$ & 276 & $(44.7)$ & 14 & $(2.3)$ & 8 & $(1.3)$ & \\
\hline $16-64$ & 149 & $(15.4)$ & 418 & $(43.1)$ & 306 & $(31.5)$ & 81 & $(8.4)$ & 16 & $(1.6)$ & \\
\hline $65-74$ & 9 & $(10.5)$ & 38 & $(44.2)$ & 23 & $(26.7)$ & 13 & $(15.1)$ & 3 & $(3.5)$ & \\
\hline$>74$ & 19 & $(14.8)$ & 46 & $(35.9)$ & 29 & $(22.7)$ & 32 & $(25.0)$ & 2 & $(1.6)$ & \\
\hline $\begin{array}{l}\text { Whether the patients suspected them- } \\
\text { selves of having COVID-19 infection or not }\end{array}$ & & & & & & & & & & & $<0.001$ \\
\hline Yes & 145 & $(13.6)$ & 394 & $(36.9)$ & 414 & $(38.8)$ & 100 & $(9.4)$ & 14 & $(1.3)$ & \\
\hline No & 102 & (13.9) & 358 & $(48.7)$ & 220 & (29.9) & 40 & (5.4) & 15 & $(2.0)$ & \\
\hline Symptom severity, n (\%) & & & & & & & & & & & $<0.001$ \\
\hline Mild & 146 & $(14.9)$ & 442 & $(45.1)$ & 328 & $(33.5)$ & 48 & $(4.9)$ & 16 & $(1.6)$ & \\
\hline Moderate & 99 & $(12.6)$ & 299 & $(38.1)$ & 298 & $(38.0)$ & 75 & $(9.6)$ & 13 & $(1.7)$ & \\
\hline Severe & 2 & $(5.3)$ & 11 & (28.9) & 8 & $(21.1)$ & 17 & $(44.7)$ & 0 & $(0.0)$ & \\
\hline
\end{tabular}


result may be attributed to the fact that $\mathrm{AHHC}$ medical services provide consultations at home, using PPE when necessary, thus allowing patients to avoid contact with other patients in the hospital. A previous report also suggested that domiciliary radiography could reduce the risk of infected patients referring to family doctors' offices or emergency departments and reduce transportation costs to the hospital [23].

Third, our results are similar to those of a previous study of AHHC medical service users in Australia, in which $40 \%$ felt that they would prefer ED visits or ambulance calls if AHHC services were not available [24]. This previous study concluded that AHHC medical services appear to be associated with a reduction in ED visits [24]. Furthermore, during the COVID-19 pandemic, several previous studies have raised concerns about the increased risk of delays in receiving medical care due to patients refraining from seeking healthcare services [1-4].

Our results also revealed that some patients indicated that they would remain at home or wait until working hours if AHHC medical services were not available despite having a condition that required an ED visit or an ambulance. These patients accounted for $22.8 \%$ of all respondents in the questionnaire (411/1802). This result may reflect the existence of a situation in which patients refrain from seeking medical services in Japan. AHHC medical services in Japan provide house calls with a vehicle equipped with medical equipment and can also provide medical procedures, such as the RT-PCR test for SARS-CoV-2, rapid SARS-CoV-2 antigen test, rapid influenza diagnostic test, drip test, $\mathrm{X}$-ray, and ultrasonography. Therefore, our results suggest that AHHC medical services may be one of the strategies that can address the problem of patients avoiding visits to healthcare facilities during the COVID-19 pandemic. In addition, those who suspected themselves of having COVID-19 infection were more likely to intend to visit the ED or call an ambulance if AHHC services were not available. AHHC services may also be helpful in tackling the COVID19 pandemic, including the ability to undergo medical examinations while preventing secondary infections.

We acknowledge that there are several limitations to our study. First, this study was based on information from only one private AHHC medical service provider. Therefore, users of this AHHC medical service provider may have different characteristics from non-users, resulting in selection biases. However, this provider was the first AHHC medical service provider in Japan and had the largest AHHC medical service market share in Japan. Furthermore, before providing AHHC medical services, the provider conducted telephone triage to determine the necessity of medical services so as to provide medical services only to those considered to require medical consultation. Second, the response rate of the patient questionnaire in this study was relatively low (11.3\%), which may have led to selection bias. For example, there were differences in the proportion of patients' age, drug prescriptions, examination by health care personnel wearing PPE, and use of diagnostic tools for COVID-19 between responders and non-responders. Third, although about $40 \%$ felt that they would visit the ED or call for an ambulance if they could not use AHHC medical services, it is not clear how many patients refrained from seeking healthcare services. Further study is required to evaluate AHHC medical services in the context of overall after-hours care because our results were based on only the patient's impression who used AHHC medical services.

\section{Conclusion}

The majority of patients who received AHHC medical services felt that these services can help prevent transmission of COVID-19 because of the medical services provided in their own homes. AHHC medical services may be one of the strategies for alleviating patients' hesitation to visit healthcare facilities and may reduce the risk of delayed hospital visits during emergencies.

\section{Abbreviations \\ AHHC: After-hour house-call; COVID-19: Coronavirus disease 2019; ED: Emer- gency department; PPE: Personal protective equipment; SARS-CoV-2: Severe acute respiratory syndrome coronavirus 2 .}

\section{Acknowledgements}

We would like to thank Editage (www.editage.com) for English language editing.

\section{Authors' contributions}

$\mathrm{KM}$ and $\mathrm{RI}$ contributed to the design of the study and manuscript preparation. KM contributed to the data analysis. All authors contributed to the interpretation of the data and critical review of the manuscript. All authors approved the final manuscript.

\section{Funding}

This work was supported by grants from the Fast Doctor Ltd. The funder had no role in the design, methods, analysis, and preparation of the paper.

\section{Availability of data and materials}

The data that support the findings of this study are available from Fast Doctor Ltd., but restrictions apply to the availability of these data, which were used under license for the current study, and so are not publicly available.

\section{Declarations}

\section{Ethics approval and consent to participate}

We conducted this study according to the ethical guidelines of our institution (approval by the research ethics committee of the University of Tsukuba: 1527) in accordance with the principles of the Declaration of Helsinki. The requirement for informed patient consent was waived because of the anonymous nature of the data by the ethics committee of the University of Tsukuba. 


\section{Consent for publication \\ Not applicable.}

\section{Competing interests}

Fast DOCTOR Ltd. sponsored RI's joint appointment as an associate professor at the University of Tsukuba. Fast DOCTOR Ltd. also sponsored KM's XJ's appointment as an assistant professor at the University of Tsukuba. IM and NT have no conflict of interest.

Received: 24 March 2021 Accepted: 31 August 2021

Published online: 15 September 2021

\section{References}

1. Lazzerini M, Barbi E, Apicella A, Marchetti F, Cardinale F, Trobia G. Delayed access or provision of care in Italy resulting from fear of COVID-19. Lancet Child Adolesc Health. 2020;4:e10-1.

2. Jeffery MM, D'Onofrio G, Paek H, Platts-Mills TF, Soares WE 3rd, Hoppe JA, et al. Trends in emergency department visits and hospital admissions in health care systems in 5 states in the first months of the COVID-19 pandemic in the US. JAMA Intern Med. 2020;180:1328-33.

3. Kastritis E, Tsitsimpis K, Anninos E, Stamatelopoulos K, Kanakakis I, Lampropoulos $C$, et al. Significant reduction in the visits to the emergency room department during the COVID-19 pandemic in a tertiary hospital in Greece: indirect victims of the pandemic? Med (Baltim). 2020;99:e23845.

4. Lynn RM, Avis JL, Lenton S, Amin-Chowdhury Z, Ladhani SN. Delayed access to care and late presentations in children during the COVID-19 pandemic: a snapshot survey of 4075 paediatricians in the UK and Ireland. Arch Dis Child. 2021;106:e8.

5. Sharma R, Kuohn LR, Weinberger DM, Warren JL, Sansing LH, Jasne A, et al. Excess cerebrovascular mortality in the United States During the COVID-19 pandemic. Stroke. 2021;52:563-72.

6. Mantica G, Riccardi N, Terrone C, Gratarola A. Non-COVID-19 visits to emergency departments during the pandemic: the impact of fear. Public Health. 2020;183:40-1.

7. Seminara D, Szerszen A, Maese JR, Shah Z. Medical home visit programs during COVID-19 state of emergency. Am J Manag Care. 2020;26:465-6.

8. Grol R, Giesen P, van Uden C. After-hours care in the United Kingdom, Denmark, and the Netherlands: new models. Health Aff (Millwood). 2006;25:1733-7.

9. Huibers L, Giesen P, Wensing M, Grol R. Out-of-hours care in western countries: assessment of different organizational models. BMC Health Serv Res. 2009;9:105.

10. Smits M, Colliers A, Jansen T, Remmen R, Bartholomeeusen S, Verheij R. Examining differences in out-of-hours primary care use in Belgium and the Netherlands: a cross-sectional study. Eur J Public Health. 2019;29:1018-24.
11. Giesen P, Smits M, Huibers L, Grol R, Wensing M. Quality of after-hours primary care in the Netherlands: a narrative review. Ann Intern Med. 2011;155:108-13.

12. Otsuki H, Murakami Y, Fujino K, Matsumura K, Eguchi Y. Analysis of seasonal differences in emergency department attendance in Shiga Prefecture, Japan between 2007 and 2010. Acute Med Surg. 2016;3:74-80.

13. Kawakami C, Ohshige K, Kubota K, Tochikubo O. Influence of socioeconomic factors on medically unnecessary ambulance calls. BMC Health Serv Res. 2007;7:120.

14. Ehara A. Accessibility of pediatric inpatient services in Japan. PLOS ONE. 2018;13:e0201443.

15. Sakamoto H, Rahman M, Nomura S, Okamoto E, Koike S, Yasunaga H, et al. Japan health system review. In: Vol. 8 No. 1. New Delhi: World Health Organization, Regional Office for South-East Asia; 2018

16. Kaneko M, Inoue M, Okubo M, Furgal AKC, Crabtree BF, Fetters MD. Differences between frequent emergency department users in a secondary rural hospital and a tertiary suburban hospital in central Japan: a prevalence study. BMJ Open 2020;10:e039030.

17. Sakurai A, Morimura N, Takeda M, Miura K, Kiyotake N, Ishihara T, et al. A retrospective quality assessment of the 7119 call triage system in Tokyo - telephone triage for non-ambulance cases. J Telemed Telecare. 2014;20:233-8.

18. Morimura N, Aruga T, Sakamoto T, Aoki N, Ohta S, Ishihara T, et al. The impact of an emergency telephone consultation service on the use of ambulances in Tokyo. Emerg Med J. 2011;28:64-70.

19. Looi MK. Covid-19: Japan declares state of emergency as Tokyo cases soar. BMJ. 2020;369:m1447.

20. Mitchell RD, O'Reilly GM, Mitra B, Smit V, Miller JP, Cameron PA. Impact of COVID-19 State of Emergency restrictions on presentations to two Victorian emergency departments. Emerg Med Australas. 2020;32:1027-33.

21. Hughes HE, Hughes TC, Morbey R, Challen K, Oliver I, Smith GE, et al. Emergency department use during COVID-19 as described by syndromic surveillance. Emerg Med J. 2020;37:600-4.

22. Walker LE, Heaton HA, Monroe RJ, Reichard RR, Kendall M, Mullan AF, et al. Impact of the SARS-CoV-2 pandemic on emergency department presentations in an integrated health system. Mayo Clin Proc. 2020;95:2395-407.

23. Zanardo M, Schiaffino S, Sardanelli F. Bringing radiology to patient's home using mobile equipment: A weapon to fight COVID-19 pandemic. Clin Imaging. 2020;68:99-101.

24. Ifediora CO, Rogers GD. Patient-reported impact of after-hours house-call services on the utilization of emergency department services in Australia. Fam Pract. 2017;34:593-8.

\section{Publisher's Note}

Springer Nature remains neutral with regard to jurisdictional claims in published maps and institutional affiliations.
Ready to submit your research? Choose BMC and benefit from:

- fast, convenient online submission

- thorough peer review by experienced researchers in your field

- rapid publication on acceptance

- support for research data, including large and complex data types

- gold Open Access which fosters wider collaboration and increased citations

- maximum visibility for your research: over 100M website views per year

At BMC, research is always in progress.

Learn more biomedcentral.com/submissions 